
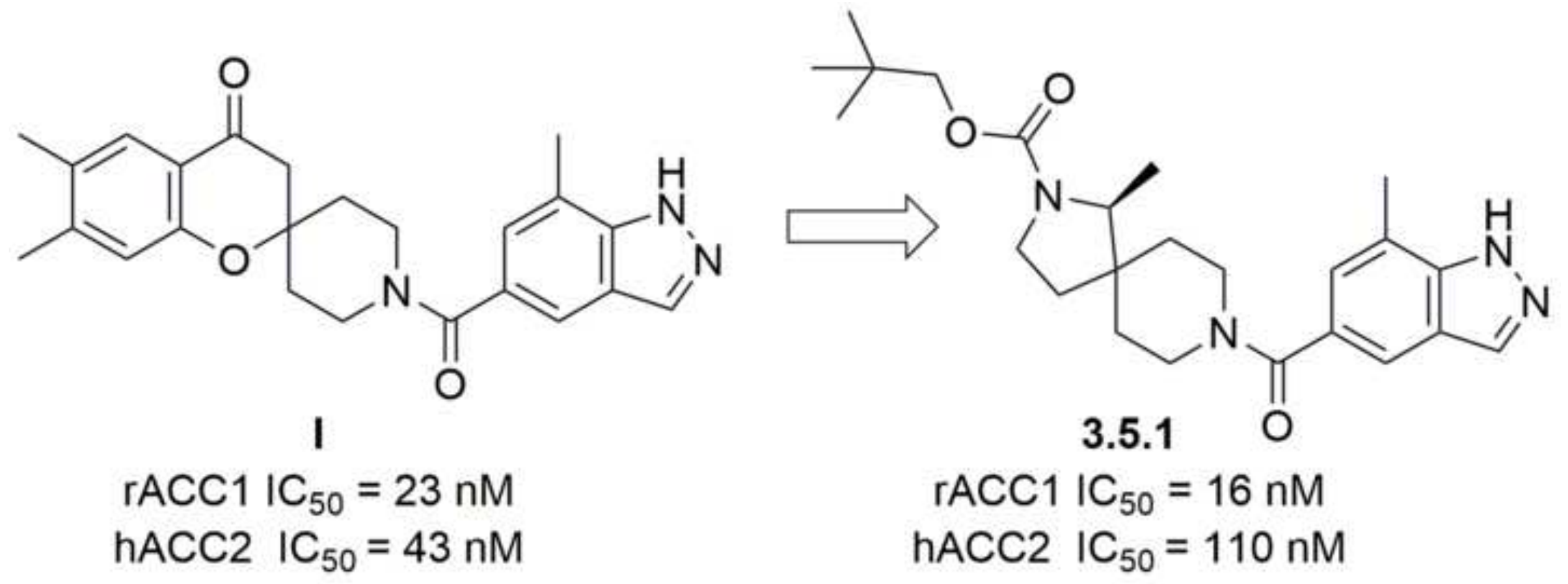


\title{
Discovery of spirocyclic-diamine inhibitors of mammalian acetyl CoA-carboxylase
}

Daniel W. Kung ${ }^{\mathrm{a}, \mathrm{h}, *}$, David A. Griffith ${ }^{\mathrm{a}, \mathrm{g}, *}$, William P. Esler ${ }^{\mathrm{b}, \mathrm{g}}$, Felix F. Vajdos ${ }^{\mathrm{ch}}$, Alan M. Mathiowetz $^{\mathrm{a}, \mathrm{g}}$, Shawn D. Doran ${ }^{\mathrm{d}, \mathrm{h}}$, Paul A. Amor ${ }^{\mathrm{b}, \mathrm{g}}$, Scott W. Bagley ${ }^{\mathrm{a}, \mathrm{h}}$, Tereece Banks ${ }^{\mathrm{a}, \mathrm{h}}$, Shawn Cabral ${ }^{\mathrm{a}, \mathrm{h}}$, Kristen Ford $^{\mathrm{e}, \mathrm{h}}$, Carmen N. Garcia-Irizarry ${ }^{\mathrm{a}, \mathrm{h}}$, Margaret S. Landis ${ }^{\mathrm{f}, \mathrm{h}}$, Kathrine Loomis $^{\mathrm{b}, \mathrm{h}}$, Kirk McPherson ${ }^{\mathrm{b}, \mathrm{h}}$, Mark Niosi ${ }^{\mathrm{d}, \mathrm{h}}$, Kristin L. Rockwell ${ }^{\mathrm{e} h}$, Colin Rose ${ }^{\mathrm{a}, \mathrm{h}}$, Aaron C. Smith ${ }^{\mathrm{a}, \mathrm{h}}$, James A. Southers ${ }^{\mathrm{a}, \mathrm{h}}$, Susan Tapley ${ }^{\mathrm{b}, \mathrm{h}}$, Meihua Tu ${ }^{\mathrm{a}, \mathrm{g}}$, James J. Valentine $e^{\mathrm{e}, \mathrm{h}}$

${ }^{a}$ Worldwide Medicinal Chemistry, ${ }^{b}$ Cardiovascular, Metabolic and Endocrine Diseases Research

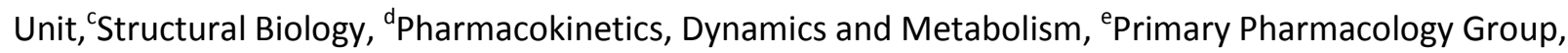
and ${ }^{f}$ Pharmaceutical SciencesResearch Formulations, Pfizer Worldwide Research and Development, ${ }^{g}$ Cambridge, Massachusetts 02139 and ${ }^{\mathrm{h}}$ Groton, Connecticut 06340, United States

*Corresponding authors. DWK: tel 860-715-1208, emaildaniel.w.kung@pfizer.com. DAG: tel 617-5513287, email david.a.griffith@pfizer.com.

\section{Graphical Abstract}

\begin{abstract}
A novel series of spirocyclic-diamine based, isoform non-selective inhibitors of acetyl-CoA carboxylase (ACC) is described. Thesespirodiamine derivatives were discovered by design of a library to mimic the structural rigidity and hydrogen-bonding pattern observed in the co-crystal structure of spirochromanone inhibitor I. The lead compound 3.5.1 inhibited de novo lipogenesis in rat hepatocytes, with an $\mathrm{IC}_{50}$ of $0.30 \mu \mathrm{M}$.
\end{abstract}

\section{Keywords}


spirocycle

diamine

ACC

acetylCoA-carboxylase

Fundamental imbalances in lipid metabolism have been hypothesized to contribute to the pathogenesis of non-alcoholic fatty liver disease (NAFLD), insulin resistance and type 2 diabetes mellitus (T2DM). ${ }^{1-}$ ${ }^{3}$ Elevated rates of hepatic de novo lipogenesis (DNL) and suppressed basal fatty acid oxidation are believed to contribute to net ectopic accumulation of lipid species in liver and skeletal muscle. ${ }^{3}$ Accumulation of lipid species including diacylglycerol ${ }^{1,4,5}$ and ceramides ${ }^{6}$ has been postulated to underlie the pathogenesis of insulin resistance. This mechanism is supported by the inverse relationship

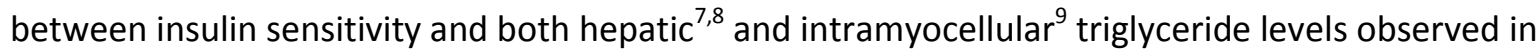
rodent models and in humans, and in some (but not all) transgenic rodent studies. ${ }^{1}$ Acetyl-CoA carboxylase (ACC) is a critical regulator of lipid metabolism, controlling the switch between lipogenicand

oxidativemetabolism. ${ }^{10}$ ACC catalyzes the ATP-dependent condensation of acetyl-CoA with carbonate to form malonyl-CoA. Malonyl-CoA is an essential substrate for DNL and regulates fatty acid oxidation through allosteric inhibition of carnitine palmitoyltransferase $1 .{ }^{11} \mathrm{ACC}$ enzyme inhibition suppresses DNL and promotes fatty acid oxidation leading to lower ectopic lipid levels. These changes may also lead to improvements ininsulin sensitivity. Suppression of ACC activity in rodents decreases tissue malonyl CoA levels, increases fatty acid oxidation and/or inhibits lipogenesis, and reduces triglyceride accumulation in skeletal muscle and/or liver. These changes improve insulin sensitivity as demonstrated withanti-sense oligonucleotides ${ }^{12}$ and some small molecule inhibitors. ${ }^{13,14}$ Pharmacologic ACC inhibitors may therefore have utility in the treatment of NAFLD and T2DM; ${ }^{15}$ the first human clinical data on a small molecule ACC inhibitor have recently been disclosed. ${ }^{16}$

Figure 1.ACC inhibitors I and II. Rat ACC1 ( $\mathrm{rACC} 1$ ) and human ACC2 (hACC2) potencies, geometric mean with $95 \%$ confidence intervals reported in parentheses; $\mathrm{hCL}_{\text {int }}$ : intrinsic clearance in human liver microsomal incubations. 
There are two closely related isoforms of ACC termed ACC1 and ACC2. We sought dual inhibitors because inhibition of both isoforms may be important to maximize pharmacological effects on lipid metabolism and efficacy. The spirochromanone ${ }^{17}(\mathbf{I})$ and spiroketopyrazole ${ }^{18}$ (II) series of compounds inhibit ACC by binding to the carboxyltransferase (CT) domain, and the potency of these compounds provided attractive starting points for identification of an alternate chemical series of ACC inhibitors. In assessing the structures and associated properties of these compounds, the ketone functional group was identified as a potential risk. The possibility of in vivo reduction of the ketone (and possible reoxidation of the resulting alcohol) was a concern because of the difficulty of predicting the extent of this metabolic pathway in humans. Further, the possible electrophilic reactivity of the ketone was a safety risk that we sought to mitigate. Analysis of the SAR and inspection of co-crystal structures in the spirochromanone series led to two guiding hypotheses: (a) the two hydrogen bond acceptor functional groups (amide and ketone carbonyls) were important for binding potency, and (b) the structural rigidity imparted by the spirocyclic ring system made significant contributions to binding by decreasing the entropic penalty for properly orienting the hydrogen bond acceptors.

Figure 2.Library design: $\mathrm{R}$ or $\mathrm{R}^{\prime}$ contains a suitable hydrogenbond acceptor.

In order to identify an alternate, non-ketonic structural series, the two hypotheses outlined above were coupled to a synthetic strategy thatleveraged the diversity of our corporate compound collection in combination with efficient synthetic chemistry. The 5-carboxy-7-methyl-indazole derived amide, which demonstrated high relative contributions to potency and ligand efficiency in the spirochromanones, was selected as an "anchor" group for design of a library that would couple the corresponding carboxylic acid to amines intended to mimic the spirochromanone scaffold and its ketone hydrogen bond acceptor (Figure 2). The synthetic chemistry to couple 5-carboxy-7-methyl-indazole to cyclic secondary amines under standard amidation conditions was well established. ${ }^{18} \mathrm{Cyclic}$ secondary amines with distal hydrogen bonding groups (most commonly, carbonyls such as amides or carbamates) were selected as the amine coupling partners for this library. 


\begin{tabular}{|c|c|c|c|c|c|c|}
\hline Cmpd & Ring $A$ & Ring B & eLogD & $\begin{array}{l}\text { rACC1 } \\
(\mu \mathrm{M})\end{array}$ & $\begin{array}{c}\text { hACC2 } \\
(\mu \mathrm{M})\end{array}$ & $\begin{array}{c}\mathrm{hCL}_{\text {int }} \\
(\mathrm{mL} / \mathrm{min} / \mathrm{kg})\end{array}$ \\
\hline 1.1 & 6 & 5 & 2.8 & $\begin{array}{c}1.0 \\
(0.67-1.6)\end{array}$ & $\begin{array}{c}2.2 \\
(1.5-3.2)\end{array}$ & 94 \\
\hline 1.2 & 5 & 6 & 3.0 & $\begin{array}{c}0.51 \\
(0.36-0.73)\end{array}$ & $\begin{array}{c}1.0 \\
(0.90-1.2)\end{array}$ & 32 \\
\hline 1.3 & 6 & 4 & 2.5 & $\begin{array}{c}0.81 \\
(0.78,0.84)^{*}\end{array}$ & $\begin{array}{c}2.4 \\
(0.98-5.7)\end{array}$ & 19 \\
\hline 1.4 & 4 & 6 & 2.6 & $\begin{array}{c}0.45 \\
(0.38-0.53)\end{array}$ & $\begin{array}{c}0.80 \\
(0.50-1.3)\end{array}$ & $<9$ \\
\hline 1.5 & 5 & 5 & $2.6^{!}$ & $\begin{array}{c}11 \\
(7.4,17)^{*}\end{array}$ & $\begin{array}{c}20 \\
(7.7-51)\end{array}$ & ND \\
\hline 1.6 & 4 & 4 & $2.2^{!}$ & $>30$ & $>10$ & ND \\
\hline
\end{tabular}

Table 1. $\mathrm{N}$-t-Butoxycarbonyl-substituted spirodiamine ACC inhibitors.rACC1 and hACC2 potencies are generally the geometric mean of at least 3 replicates ( $95 \%$ confidence interval in parentheses). ${ }^{*}$ For $n=$ 2 replicates, the individual measurements are reported in parentheses. 'Calculated eLogD.

Inhibition of rat ACC1 and human ACC2 was assayed as described in the literature. ${ }^{18}$ Several hits from theinitial library came from a sub-class of compounds derived from t-butyl carbamate-capped spirodiamine cores. ${ }^{19,20-27} \mathrm{~A}$ second iteration of compounds was synthesized to provide the full set of permutations shown in Table 1. Modeling (not shown) into the co-crystal structure of spirochromanonel enabled the conclusions that a 4,4-system (1.6) was too short to span the necessary distance between the hypothesized $\mathrm{H}$-bonding groups and that the 5,5-core (1.5) was too angular to be well-matched to the shape of the binding pocket. However, the similar potencies of the 5,6- and 4,6spirodiamine cores (in both orientations) provided reasonable starting potency for initial hits.

A co-crystal structure of the most potent derivative, azetidine-piperidine 1.4 ,overlaid with the bound conformation ofspirochromanonel(Figure 3 ) showed that while spirochromanone1made two hydrogen bonds to the protein (the ketone to backbone Gly-B1958; and the amide to backbone Glu-B2026), the carbamate-Gly-B1958 distance for 1.4 was too long (O-to-N distance of $3.8 \AA$ ) to form a productive hydrogen bond, although there may be a generally favorable electrostatic interaction between the carbamate and the backbone $\mathrm{NH}$ of Gly-B1958. This 20-fold loss in potency relative to spirochromanonelwas consistent with our initial hypothesis that this $\mathrm{H}$-bond was critical for potency.A crystal structure of the pyrrolidine-piperidine 1.2was not obtained;however, modeling suggested that 
the greater angularity in the core might allow a more optimal $\mathrm{H}$-bond distance; a subsequent $\mathrm{X}$-ray structure of a related derivative showed a shorter $\mathrm{H}$-bond distance (vide infra, compound 3.5.1).

Although the overall lipophilicity of both orientations of the 5,6- and 4,6-spirodiamine derivatives 1.11.4 were similar $\left(\operatorname{elog}^{28}\right.$ ), the analogues exhibited differential stability in a human liver microsomal clearance (HLM) assay. The orientation of the cores with the piperidine nitrogen capped as the amide was more stable in HLM than the orientation with the piperidine capped as a t-butyl carbamate. The general correlation between lipophilicity and HLM clearance for these spirodiamine derivatives suggested that the elogD range of $\sim 2.5-3.0$ was where the transition from lower to higher clearance occurred, as exemplified by the compounds in Table 1. The clearance of the 4,6-derivative 1.4 was attractive $(<9 \mathrm{~mL} / \mathrm{min} / \mathrm{kg})$, although that of the 5,6-derivative 1.2 was higher than desired (32 $\mathrm{mL} / \mathrm{min} / \mathrm{kg})$.

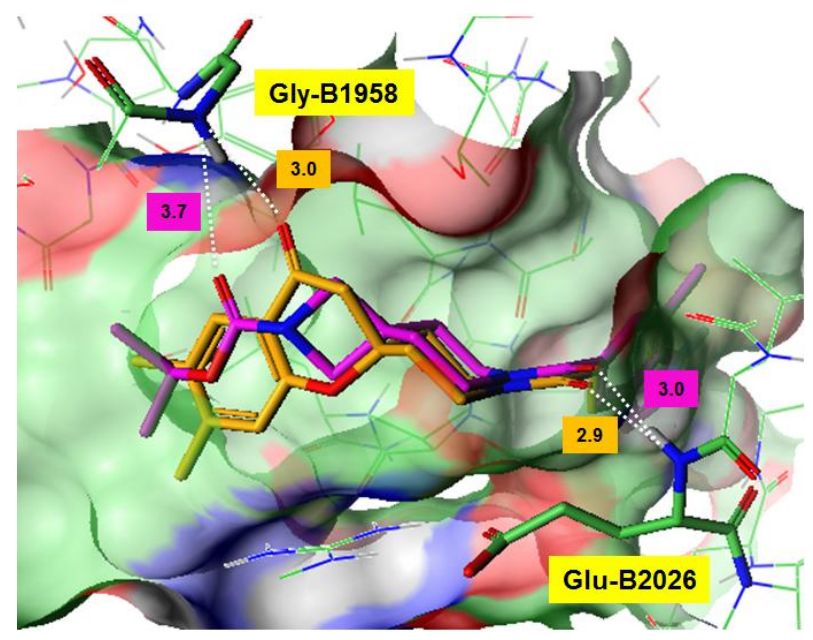

Figure 3.Co-crystal structure of1.4 (pink)in the CT-domain of $A C C$, overlaid with the bound conformation ofI(orange).pdb accession codes: I, 5CTB; 1.4,5CTC.

Based on the combination of the potency and metabolism trends, further optimization was focused on the piperidine-amide functionalized 5,6- and 4,6-cores (as exemplified by compounds $\mathbf{1 . 2}$ and 1.4, respectively). We focused initially on searching for substituents thatwould provide an optimal fit in the ACC binding pocket. The X-ray co-crystal structure of compound $\mathbf{1 . 4}$ showed that the protein region around the carbamate substituent was composed primarily of hydrophobic side chains that did not form a well-fitting pocket around the t-butyl group. There appeared to be an opportunity to enhance potency through improved interactions with these hydrophobic side chains, and perhaps some probability of inducing a better-defined pocket through changes to the ligand structure. From consideration of physicochemical properties, introduction of polar groups in the carbamate substituent was desirable; however, in balancing synthetic efficiency (number of compounds) with desirable properties, some final compounds that were more lipophilic than ultimately desired were selected. For example, a phenyl derivative was considered to be a useful single representative compound to evaluate the shape of "sixmembered aromatic ring"; the knowledge that lipophilicity could subsequently be decreased by 
incorporation of a pyridine or other heteroaryl ring in place of the phenyl was explicitly considered. Thus, in some cases only the phenyl derivative was selected, based on the hypothesis that weak or no measurable binding potency for phenyl would be sufficient to conclude that "six-membered aromatic ring" was not a tolerated shape. If phenyl were sufficiently active, a follow-up round of synthesis was planned to examine lipophilicity-decreasing changes, such as the introduction of polar substituents on the phenyl ring or the substitution of heteroaryls for phenyl. This strategic decision, while reducing the number of compounds to be synthesized, carried the implicit risk of "missing" potency-enhancing polar interactions between ligand and protein.

Scheme 1.Synthetic routes to carbamate-spirodiamine-amide derivatives.(a) Indazole-acid chloride, i- $\mathrm{Pr}_{2} \mathrm{NEt}, \mathrm{CH}_{2} \mathrm{Cl}_{2}$, or indazole-acid, EDC, $\mathrm{HOBt}, \mathrm{Et}_{3} \mathrm{~N}, \mathrm{DMAc}$, (b) $\mathrm{TFA}, \mathrm{CH}_{2} \mathrm{Cl}_{2}$, (c) $\mathrm{ROCOCl}, \mathrm{Et}_{3} \mathrm{~N}, \mathrm{CH}_{2} \mathrm{Cl}_{2}$, or $\mathrm{ROH}, \mathrm{CDI}, \mathrm{Et}_{3} \mathrm{~N}, \mathrm{CH}_{2} \mathrm{Cl}_{2}$, or $\mathrm{ROH}, 4-\mathrm{NO}_{2} \mathrm{PhCOCl} \mathrm{Et}_{3} \mathrm{~N}, \mathrm{CH}_{2} \mathrm{Cl}_{2}$.

Although a range of carbamate substituents was examined on the azetidine-piperidine and pyrrolidinepiperidine cores, only a small subset demonstrated potency comparable to the t-butyl starting points (Table 2). The three-dimensional shape presented by the t-butyl group of the original hits is mimicked in several of the more potent compounds. Although the 4,6-derivatives $\mathbf{2 . 1}$ (neopentyl) and $\mathbf{2 . 2}((R)-\alpha$ methyl-benzyl) maintained similar potency to the original t-butyl derivative 1.4, the corresponding carbamate substituents on the 5,6-core provided greater improvements in potency. The $(R)$-enantiomer of $\alpha$-methyl-benzyl (2.6) provided a new benchmark for potency. Notably, however, the potencyenhancing structural changes were all accompanied by increased lipophilicity, which also correlated with increased turnover in HLM. Attempts to decrease overall lipophilicity by substitution with heteroaryl rings or atoms led to reduced potencies and failed to provide compounds with suitably balanced properties.

\begin{tabular}{ccccccc}
\hline Cmpd & Ring A & $R$ & eLogD & $\begin{array}{c}\text { rACC1 } \\
(\mu \mathrm{M})\end{array}$ & $\begin{array}{c}\mathrm{hACC2} \\
(\mu \mathrm{M})\end{array}$ & $\begin{array}{c}\mathrm{hCL}_{\text {int }} \\
(\mathrm{mL} / \mathrm{min} / \mathrm{kg})\end{array}$ \\
\hline
\end{tabular}




\begin{tabular}{|c|c|c|c|c|c|}
\hline 2.1 & 4 & $\mathrm{CH}_{2} \mathrm{tBu}$ & $3.3^{!}$ & $\begin{array}{c}0.31 \\
(0.19,0.49)^{*}\end{array}$ & $\begin{array}{c}1.4 \\
(0.69-3.0)\end{array}$ \\
\hline 2.2 & 4 & $(R)-\alpha-M e B n$ & 3.4 & $\begin{array}{c}0.31 \\
(0.23,0.43)^{*}\end{array}$ & $\begin{array}{c}0.88 \\
(0.44-1.7)\end{array}$ \\
\hline 2.3 & 5 & $\mathrm{iPr}$ & $2.0^{!}$ & $\begin{array}{c}1.6 \\
(1.4,1.7)^{*}\end{array}$ & $\begin{array}{c}4.5 \\
(2.1-9.8)\end{array}$ \\
\hline 2.4 & 5 & $\mathrm{CH}_{2} \mathrm{tBu}$ & 3.6 & $\begin{array}{c}0.22 \\
(0.12-0.39)\end{array}$ & $\begin{array}{c}0.80 \\
(0.44-1.5)\end{array}$ \\
\hline 2.5 & 5 & $\mathrm{Bn}$ & $3.2^{!}$ & $\begin{array}{c}2.1 \\
(1.6,2.7)^{*}\end{array}$ & $\begin{array}{c}4.0 \\
(3.0-5.3)\end{array}$ \\
\hline 2.6 & 5 & $(R)-\alpha-\mathrm{MeBn}$ & 3.6 & $\begin{array}{c}0.065 \\
(0.065,0.065)^{*}\end{array}$ & $\begin{array}{c}0.26 \\
(0.16-0.42)\end{array}$ \\
\hline
\end{tabular}

Table 2.Carbamate capped spirodiamine ACC inhibitors. rACC1 and hACC2 potencies are generally the geometric mean of at least 3 replicates (95\% confidence interval in parentheses). * For $n=2$ replicates, the individual measurements are reported in parentheses.'Calculated eLogD.

Concluding that variation of the carbamate substituents had not identified structural changes that made efficient enough use of added molecular weight and lipophilicity, we focused alternatively on small substitutions on the spirodiamine cores to seek enhanced binding interactions between the core and the protein. We chose to synthesize methyl-substituted diamine cores to probe for vectors or pockets that would provide additional binding energy. In particular, we highlighted methyl substituents at the positions adjacent to the amide and carbamate functional groups, as these substitutions were expected to provide some rotational bias around the amide/carbamate.The synthesis of the range of methylsubstituted spiroazetidine- and pyrrolidine-piperidine core structureswill be reported separately; ${ }^{29}$ from the corresponding $\mathrm{N}$-Boc diamines, synthesis of the final compounds shown in Table 3 was analogous to the route shown in Scheme 1 for the des-methyl derivatives, providing either t-butyl or neopentyl carbamates, depending on the Boc-protected diamine starting material.

\begin{tabular}{cccccccc}
\hline Cmpd & Core & $\mathrm{R}$ & $\mathrm{R}^{\prime}, \mathrm{R}^{\prime \prime},\left(\mathrm{R}^{\prime \prime \prime}\right)$ & eLogD & $\begin{array}{c}\mathrm{rACC} 1 \\
(\mu \mathrm{M})\end{array}$ & $\begin{array}{c}\mathrm{hACC2} \\
(\mu \mathrm{M})\end{array}$ & $\begin{array}{c}\mathrm{hCL}_{\text {int }} \\
(\mathrm{mL} / \mathrm{min} / \mathrm{kg})\end{array}$ \\
\hline 3.1 & $\mathrm{~A}$ & $\mathrm{tBu}$ & $\mathrm{Me}, \mathrm{H}$ & 2.6 & $\begin{array}{c}4.8 \\
(4.2,5.5)^{*}\end{array}$ & $\begin{array}{c}9.2 \\
(4.1-20)\end{array}$ & 46 \\
3.2 & $\mathrm{~A}$ & $\mathrm{tBu}$ & $\mathrm{H}, \mathrm{Me}$ & 2.8 & $\begin{array}{c}0.24 \\
(0.90\end{array}$ & 60 \\
& & & & & $(0.19,0.30)^{*}$ & $(0.50-1.6)$ &
\end{tabular}




\begin{tabular}{|c|c|c|c|c|c|c|c|}
\hline 3.3.1 & B & $\mathrm{tBu}$ & $\mathrm{Me}, \mathrm{H}, \mathrm{H}^{\wedge}$ & $3.5^{!}$ & $\begin{array}{c}7.9 \\
(5.9,11)^{*}\end{array}$ & $\begin{array}{c}>14 \\
(3.9-50)\end{array}$ & ND \\
\hline 3.3 .2 & B & $\mathrm{tBu}$ & $\mathrm{Me}, \mathrm{H}, \mathrm{H}^{\wedge}$ & $3.5^{!}$ & $\begin{array}{c}9.3 \\
(5.9,15)^{*}\end{array}$ & $\begin{array}{c}>17 \\
(6.1-45)\end{array}$ & ND \\
\hline 3.4 .1 & B & $\mathrm{CH}_{2} \mathrm{tBu}$ & $\mathrm{H}, \mathrm{H},(\mathrm{S})-\mathrm{Me}^{\#}$ & $4.1^{!}$ & $\begin{array}{c}2.2 \\
(1.1,4.4)^{*}\end{array}$ & $\begin{array}{c}5.5 \\
(3.1-9.9)\end{array}$ & ND \\
\hline 3.4 .2 & B & $\mathrm{CH}_{2} \mathrm{tBu}$ & $\mathrm{H}, \mathrm{H},(R)-\mathrm{Me}^{\#}$ & $4.1^{!}$ & $\begin{array}{c}0.14 \\
(0.071,0.26)^{*}\end{array}$ & $\begin{array}{c}1.1 \\
(0.44-2.5)\end{array}$ & ND \\
\hline 3.5 .1 & B & $\mathrm{CH}_{2} \mathrm{tBu}$ & $\mathrm{H},(\mathrm{S})-\mathrm{Me}, \mathrm{H}^{\%}$ & 4.0 & $\begin{array}{c}0.016 \\
(0.0017-0.16)\end{array}$ & $\begin{array}{c}0.11 \\
(0.067-0.17)\end{array}$ & 106 \\
\hline 3.5 .2 & B & $\mathrm{CH}_{2} \mathrm{tBu}$ & $\mathrm{H},(R)-\mathrm{Me}, \mathrm{H}^{\%}$ & $4.0 !$ & $\begin{array}{c}0.026 \\
(0.015,0.044)^{*}\end{array}$ & $\begin{array}{c}0.20 \\
(0.052-0.74)\end{array}$ & ND \\
\hline
\end{tabular}

Table 3.Methyl-substituted spirodiamine ACC inhibitors.rACC1 and AACC2 potencies are generally the geometric mean of at least 3 replicates (95\% confidence interval in parentheses). ${ }^{*}$ For $n=2$ replicates, the individual measurements are reported in parentheses. ${ }^{\wedge}$ Diastereomers separated by chiral chromatography, relative configuration not determined."Enantiomers separated by chiral chromatography, absolute configuration assigned based on co-crystal structure of 3.5.2. ${ }^{\text {Enantiomers }}$ separated by chiral chromatography, absolute configuration tentatively assigned based on cocrystallization of racemate providing only the $(S)$-enantiomer bound. 'Calculated eLogD.

Notably, introduction of a methyl group on the piperidine ring adjacent to the amide led to significantly decreased potency on both cores (compounds 3.1, 3.3.1, 3.3.2). Presumably, this substitution negatively impacted conformation of the ring and/or amide, in addition to potential unfavorable steric interactions with the protein. In contrast, substitutions adjacent to the carbamate group had mixed effects. On the azetidine ring (3.2), potency was largely unchanged from the parent compound $\mathbf{1 . 4}$ (refer to Table 1). On the pyrrolidine ring (3.4.1 and 3.4.2), substitution on the two-carbon unit led to one enantiomer with slightly enhanced potency and one enantiomer with slightly diminished potency relative to the parent compound $\mathbf{2 . 4}$ (refer to Table 2); however, methyl substitution on the one carbon unit of the pyrrolidine provided improved potency in both enantiomersrelative to the unsubstituted derivative 2.4. Co-crystallization of the originally synthesizedracemic mixture of compounds $\mathbf{3 . 5 . 1}$ and 3.5.2 with the ACC protein construct afforded a bound structure of only the $(S)$-enantiomer, with this stereochemistry tentatively assigned tothe higher-affinityisomer, 3.5.1; however, the absolute stereochemical assignments of 3.5.1 and 3.5.2 have not been definitively confirmed.

Figure 4 shows the overlay of the bound conformations of the methyl-pyrrolidine-piperidine3.5.1and the azetidine-piperidine 1.4. The bound position of the carbamate of 3.5.1and its hydrogen bond distance $(2.8 \AA)$ were clearly distinct from the azetidine 1.4 , and much more closely mimicked the relative position of the spirochromanonel (compare to Figure 3). The methyl group of 3.5.1was directed toward a small pocket formed by backbone atoms of residues B1954-B1956 (for clarity, not shown in 
Figure 4), bounded by both hydrophobic ( $\alpha$-carbon of Gly-B1955) and polar atoms (backbone carbonyl oxygen atoms of residues B1954 and B1956).

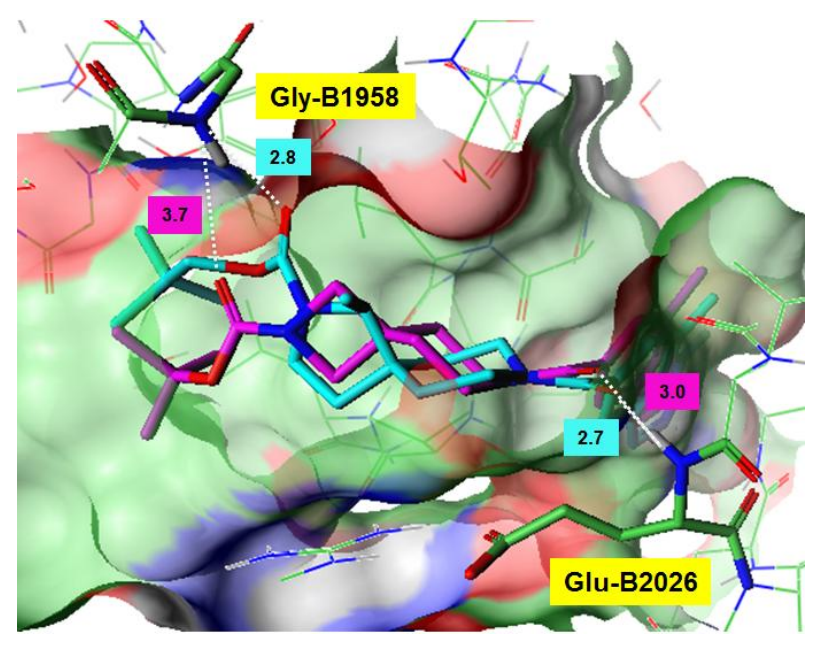

Figure 4.Co-crystal structure of $\mathbf{1 . 4}$ (pink) in the CT-domain of ACC, overlaid with the bound conformation of3.5.1 (cyan).pdb accession codes: 1.4, 5CTC; 3.5.1,5CTE.

The enhanced potency derived from the methyl-substituted pyrrolidine was sufficient for compound 3.5.1 to be characterized in an in vitro rat hepatocyte assay measuring de novo lipogenesis (Figure 5), where it demonstrated potency which was slightly diminished relative to the spiroketopyrazolell that had served as inspiration for its discovery. Unfortunately, the lipophilicity of 3.5.1 remained high, and this property translated into high clearance in vitro and in vivo $\left(\mathrm{HLM} \mathrm{CL}_{\text {int }} 106 \mathrm{~mL} / \mathrm{min} / \mathrm{kg}\right.$; rat in vivo $\mathrm{CL}_{p}$ $52 \mathrm{~mL} / \mathrm{min} / \mathrm{kg}$ ), rendering the compound unsuitable for further in vivo studies. 


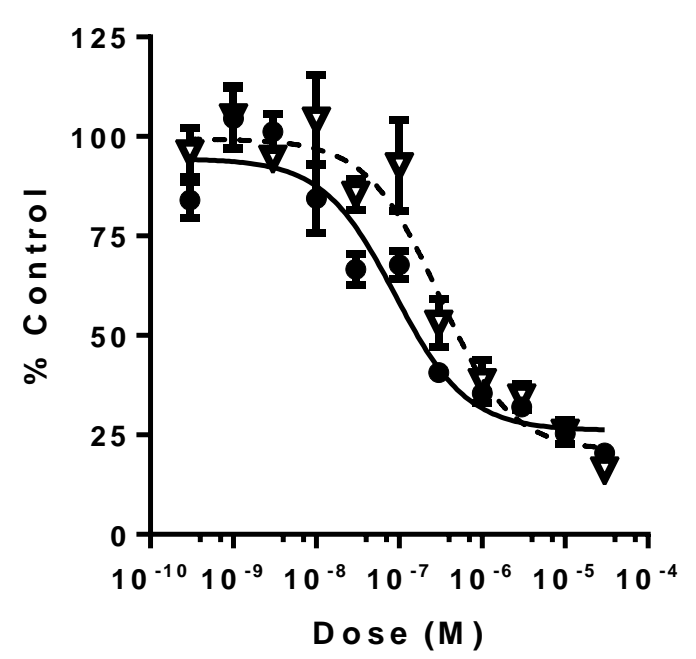

Figure 5.Inhibition of de novo lipogenesis in cryopreserved rat hepatocytes.CompoundII,solid circles and line, $I_{50}=0.093(0.051-0.17) \mu \mathrm{M} ; 3.5 .1$,open triangles with dashed line, $I_{50}=0.30(0.16-0.56) \mu \mathrm{M} ;(95 \%$ confidence intervals reported in parentheses).

In summary, toward the goal of identifying ligands that mimic the hydrogen bond acceptor pattern of known spiroketopiperidine amide ACC inhibitors, we executed a strategy based on utilizing the diversity of available conformationally-restricted amines to find initial hits. These hits were progressed to focus on a methyl-substitutedspiro-pyrrolidine-piperidine scaffold that demonstrated efficacy in a hepatocyte model of de novo lipogenesis. Further progression of these compounds will require improvedpharmacokinetic properties.

\section{Acknowledgements}

The research described herein was funded by Pfizer, Inc. The authors thank Alison Varghese and Eric Marr for technical assistance in preparation of ACC crystals. X-ray data for this study were measured at beamline X25 of the National Synchrotron Light Source. Use of the NSLS was supported by the U.S. Department of Energy, Office of Science, Office of Basic Energy Sciences under Contract No. DE-AC02$98 \mathrm{CH} 10886$. Beamline operations were supported by the DOE Office of Biological and Environmental Research, proposal E-SC0012704, and by the National Institutes of Health from grants including P41GM103473 and P41RR012408.

\section{Supplementary Material}


Methods and statistics for X-ray crystallography with compoundsI ( $p d b$ accession code 5CTB), 1.4 (5CTC), 3.5.1 (5CTE).

\section{References and Notes}

(1) Samuel, V. T.; Shulman, G. I. Cel/2012, 148, 852.

(2) Samuel, V. T.; Petersen, K. F.; Shulman, G. I. Lancet2010, 375, 2267.

(3) Savage, D. B.; Petersen, K. F.; Shulman, G. I. Physiol. Rev.2007, 87, 507.

(4) Kumashiro, N.; Erion, D. M.; Zhang, D.; Kahn, M.; Beddow, S. A.; Chu, X.; Still, C. D.; Gerhard, G. S.; Han, X.; Dziura, J.; Petersen, K. F.; Samuel, V. T.; Shulman, G. I. Proc. Natl. Acad. Sci. U.S.A.2011, 108, 16381.

(5) Bergman, B. C.; Hunerdosse, D. M.; Kerege, A.; Playdon, M. C.; Perreault, L. Diabetologia2012, 55, 1140.

(6) Larsen, P. J.; Tennagels, N. Mol. Metab.2014, 3, 252.

(7) Hwang, J. H.; Stein, D. T.; Barzilai, N.; Cui, M. H.; Tonelli, J.; Kishore, P.; Hawkins, M. Am. J. Physiol. Endocrinol. Metab.2007, 293, E1663.

(8) Korenblat, K. M.; Fabbrini, E.; Mohammed, B. S.; Klein, S. Gastroenterology2008, 134, 1369.

(9) Krssak, M.; Falk Petersen, K.; Dresner, A.; DiPietro, L.; Vogel, S. M.; Rothman, D. L.; Roden, M.; Shulman, G. I. Diabetologia1999, 42, 113.

(10) Saggerson, D. Annu. Rev. Nutr.2008, 28, 253.

(11) Obici, S.; Feng, Z.; Arduini, A.; Conti, R.; Rossetti, L. Nat. Med.2003, 9, 756.

(12) Savage, D. B.; Choi, C. S.; Samuel, V. T.; Liu, Z. X.; Zhang, D.; Wang, A.; Zhang, X. M.; Cline, G. W.; Yu, X. X.; Geisler, J. G.; Bhanot, S.; Monia, B. P.; Shulman, G. I. J. Clin. Invest.2006, 116, 817.

(13) Harwood, H. J., Jr.; Petras, S. F.; Shelly, L. D.; Zaccaro, L. M.; Perry, D. A.; Makowski, M. R.; Hargrove, D. M.; Martin, K. A.; Tracey, W. R.; Chapman, J. G.; Magee, W. P.; Dalvie, D. K.; Soliman, V. F.; Martin, W. H.; Mularski, C. J.; Eisenbeis, S. A. J. Biol. Chem.2003, 278, 37099.

(14) Schreurs, M.; van Dijk, T. H.; Gerding, A.; Havinga, R.; Reijngoud, D. J.; Kuipers, F. Diabetes Obes. Metab.2009, 11, 987.

(15) Bourbeau, M. P.; Bartberger, M. D. J. Med. Chem.2015, 58, 525.

(16) Griffith, D. A.; Kung, D. W.; Esler, W. P.; Amor, P. A.; Bagley, S. W.; Beysen, C.; CarvajalGonzalez, S.; Doran, S. D.; Limberakis, C.; Mathiowetz, A. M.; McPherson, K.; Price, D. A.; Ravussin, E.; Sonnenberg, G. E.; Southers, J. A.; Sweet, L. J.; Turner, S. M.; Vajdos, F. F. J. Med. Chem. 2014, 57, 10512.

(17) Corbett, J. W.; Freeman-Cook, K. D.; Elliott, R.; Vajdos, F.; Rajamohan, F.; Kohls, D.; Marr, E.; Zhang, H.; Tong, L.; Tu, M.; Murdande, S.; Doran, S. D.; Houser, J. A.; Song, W.; Jones, C. J.; Coffey, S. B.; Buzon, L.; Minich, M. L.; Dirico, K. J.; Tapley, S.; McPherson, R. K.; Sugarman, E.; Harwood, H. J., Jr.; Esler, W. Bioorg. Med. Chem. Lett.2010, 20, 2383.

(18) Freeman-Cook, K. D.; Amor, P.; Bader, S.; Buzon, L. M.; Coffey, S. B.; Corbett, J. W.; Dirico, K. J.; Doran, S. D.; Elliott, R. L.; Esler, W.; Guzman-Perez, A.; Henegar, K. E.; Houser, J. A.; Jones, C. S.; Limberakis, C.; Loomis, K.; McPherson, K.; Murdande, S.; Nelson, K. L.; Phillion, D.; Pierce, B. S.; Song, W.; Sugarman, E.; Tapley, S.; Tu, M.; Zhao, Z. J. Med. Chem.2012, 55, 935.

(19) Various functionalized spirodiamine derivatives have been disclosed in patent applications and in the scientific literature. For recent publications of amide and/or carbamate derivatives, see references 20-27.

(20) Weinberg, K.; Stoit, A.; Kruse, C. G.; Haddow, M. F.; Gallagher, T. Tetrahedron2013, 69, 4694. 
(21) Brown, D. G.; Bernstein, P. R.; Griffin, A.; Wesolowski, S.; Labrecque, D.; Tremblay, M. C.; Sylvester, M.; Mauger, R.; Edwards, P. D.; Throner, S. R.; Folmer, J. J.; Cacciola, J.; Scott, C.; Lazor, L. A.; Pourashraf, M.; Santhakumar, V.; Potts, W. M.; Sydserff, S.; Giguere, P.; Levesque, C.; Dasser, M.; Groblewski, T. J. Med. Chem.2014, 57, 733.

(22) Kazmierski, W. M.; Maynard, A.; Duan, M.; Baskaran, S.; Botyanszki, J.; Crosby, R.; Dickerson, S.; Tallant, M.; Grimes, R.; Hamatake, R.; Leivers, M.; Roberts, C. D.; Walker, J. J. Med. Chem.2014, 57, 2058.

(23) Du, Y.; Yang, Y.; Jiang, W.; Wang, L.; Jia, X. J.; Si, S. Y.; Chen, X. F.; Hong, B.

Molecules2012, 17, 7379.

(24) Kato, Y.; Fuchi, N.; Nishimura, Y.; Watanabe, A.; Yagi, M.; Nakadera, Y.; Higashi, E.; Yamada, M.; Aoki, T.; Kigoshi, H. Bioorg. Med. Chem. Lett.2014, 24, 565.

(25) Kato, Y.; Fuchi, N.; Saburi, H.; Nishimura, Y.; Watanabe, A.; Yagi, M.; Nakadera, Y.; Higashi, E.; Yamada, M.; Aoki, T. Bioorg. Med. Chem. Lett.2013, 23, 5975.

(26) Meyers, M. J.; Long, S. A.; Pelc, M. J.; Wang, J. L.; Bowen, S. J.; Walker, M. C.; Schweitzer, B. A.; Madsen, H. M.; Tenbrink, R. E.; McDonald, J.; Smith, S. E.; Foltin, S.; Beidler, D.; Thorarensen, A. Bioorg. Med. Chem. Lett.2011, 21, 6538.

(27) Ghosh, A. K.; Brindisi, M. J. Med. Chem.2015, 58, 2895.

(28) Lombardo, F.; Shalaeva, M. Y.; Tupper, K. A.; Gao, F. J. Med. Chem. 2001, 44, 2490.

(29) Manuscript in preparation. 


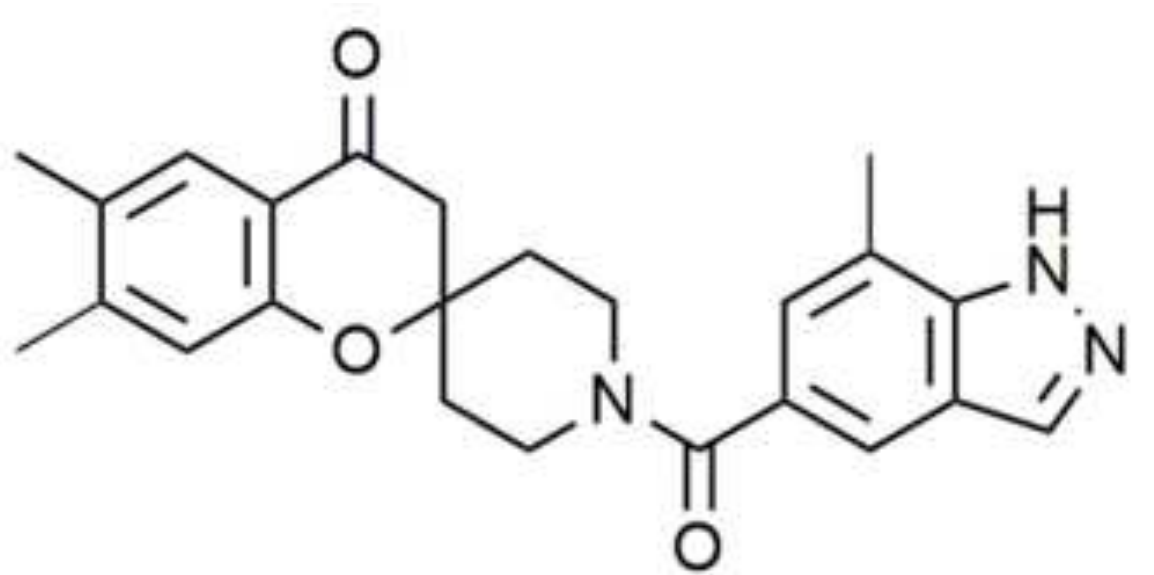

I

rACC1 IC ${ }_{50}=23(21-24) \mathrm{nM}$ hACC2 $I_{50}=43(35-54) n M$ $\mathrm{hCL}_{\text {int }}=68 \mathrm{~mL} / \mathrm{min} / \mathrm{kg}$

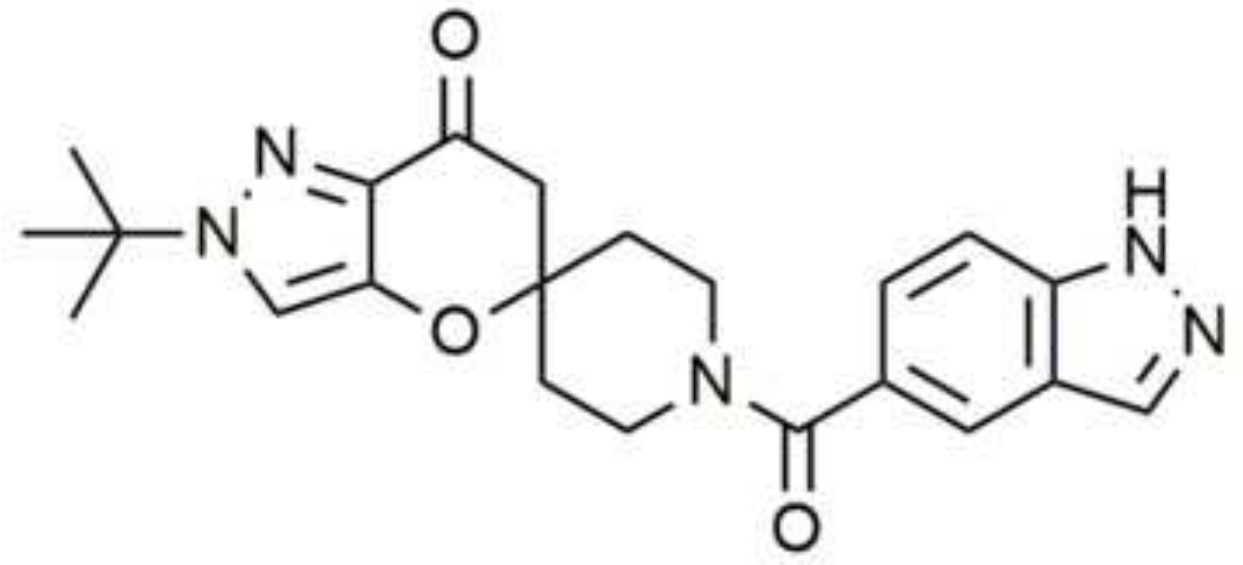

II

rACC1 IC ${ }_{50}=15(11-21) \mathrm{nM}$ $\mathrm{hACC} 2 \quad \mathrm{IC}_{50}=9.8(7.8-12) \mathrm{nM}$ $\mathrm{hCL}_{\text {int }}<9 \mathrm{~mL} / \mathrm{min} / \mathrm{kg}$ 
Figure 2

1
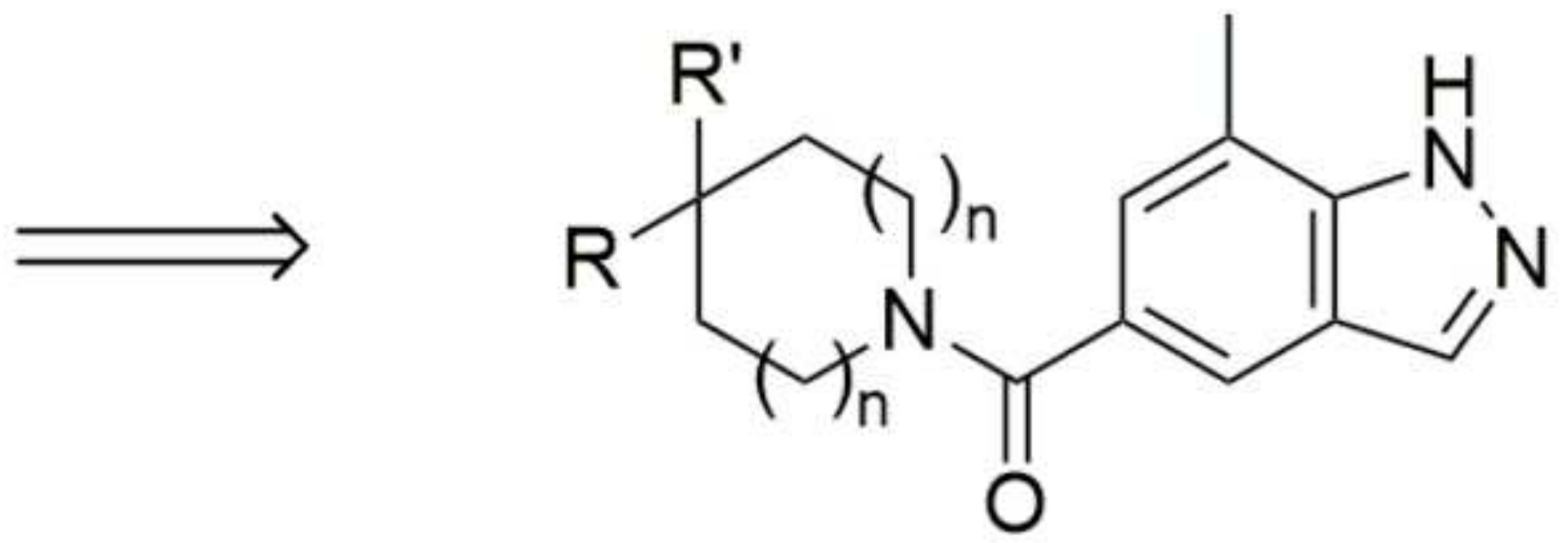


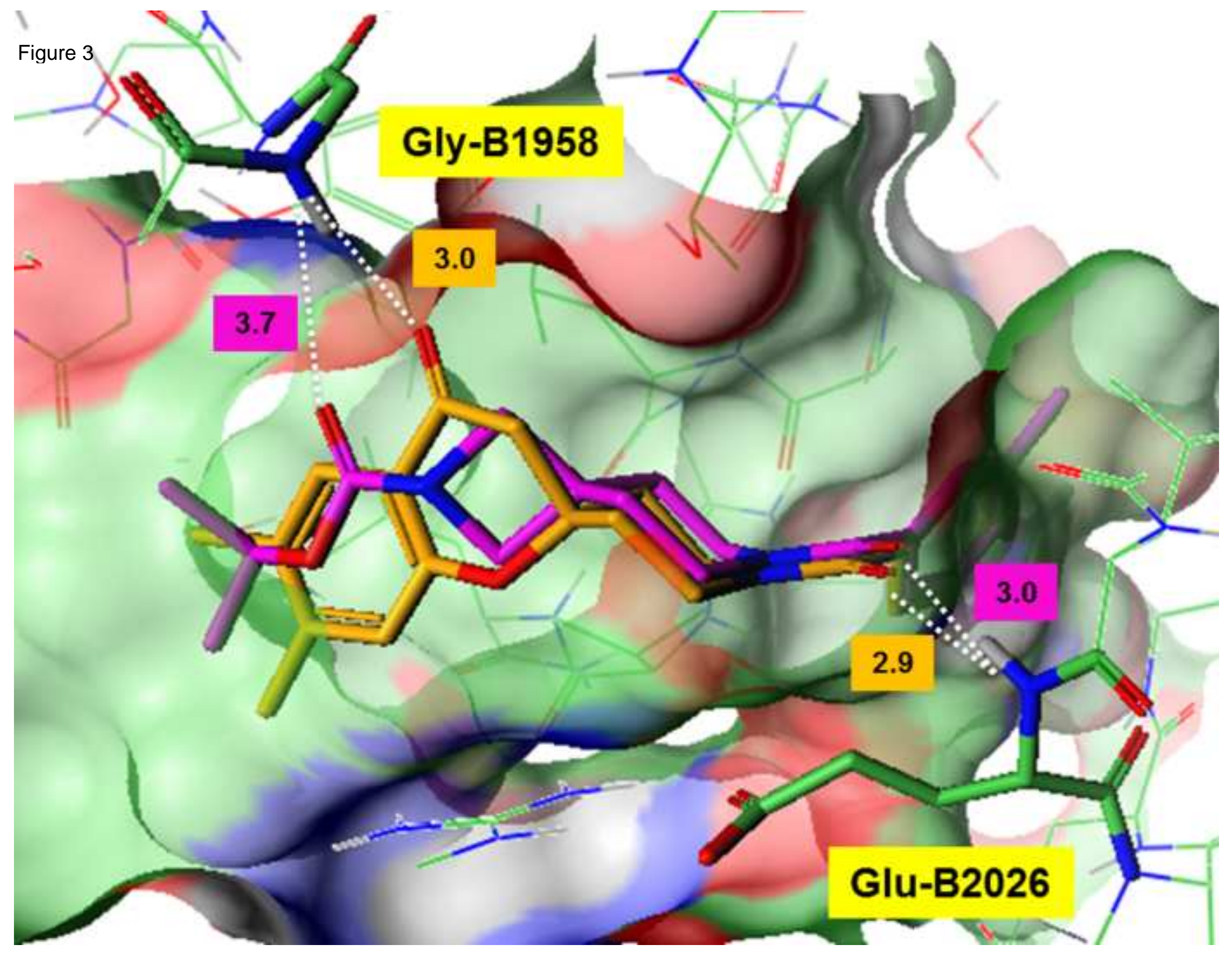




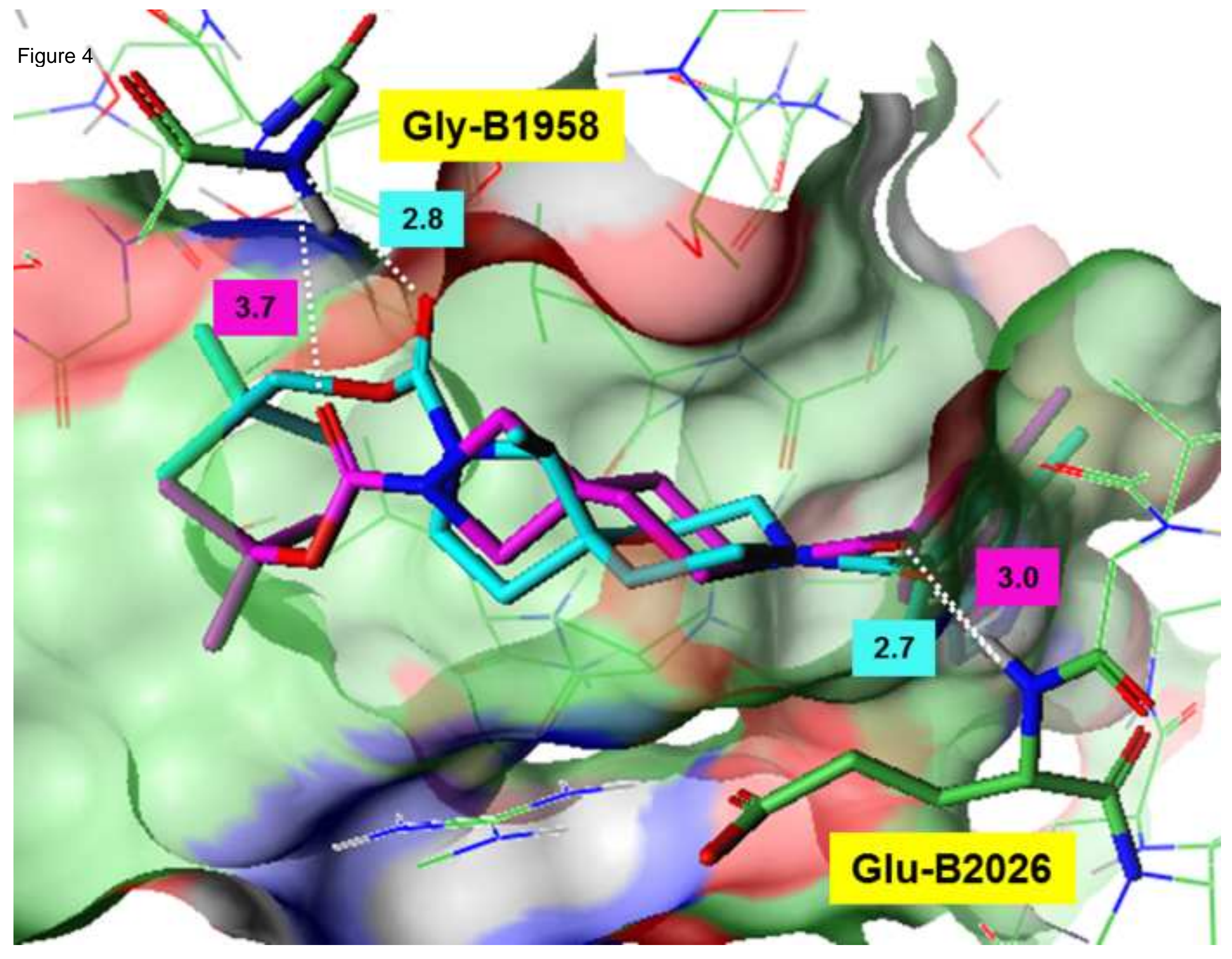


Figure 5

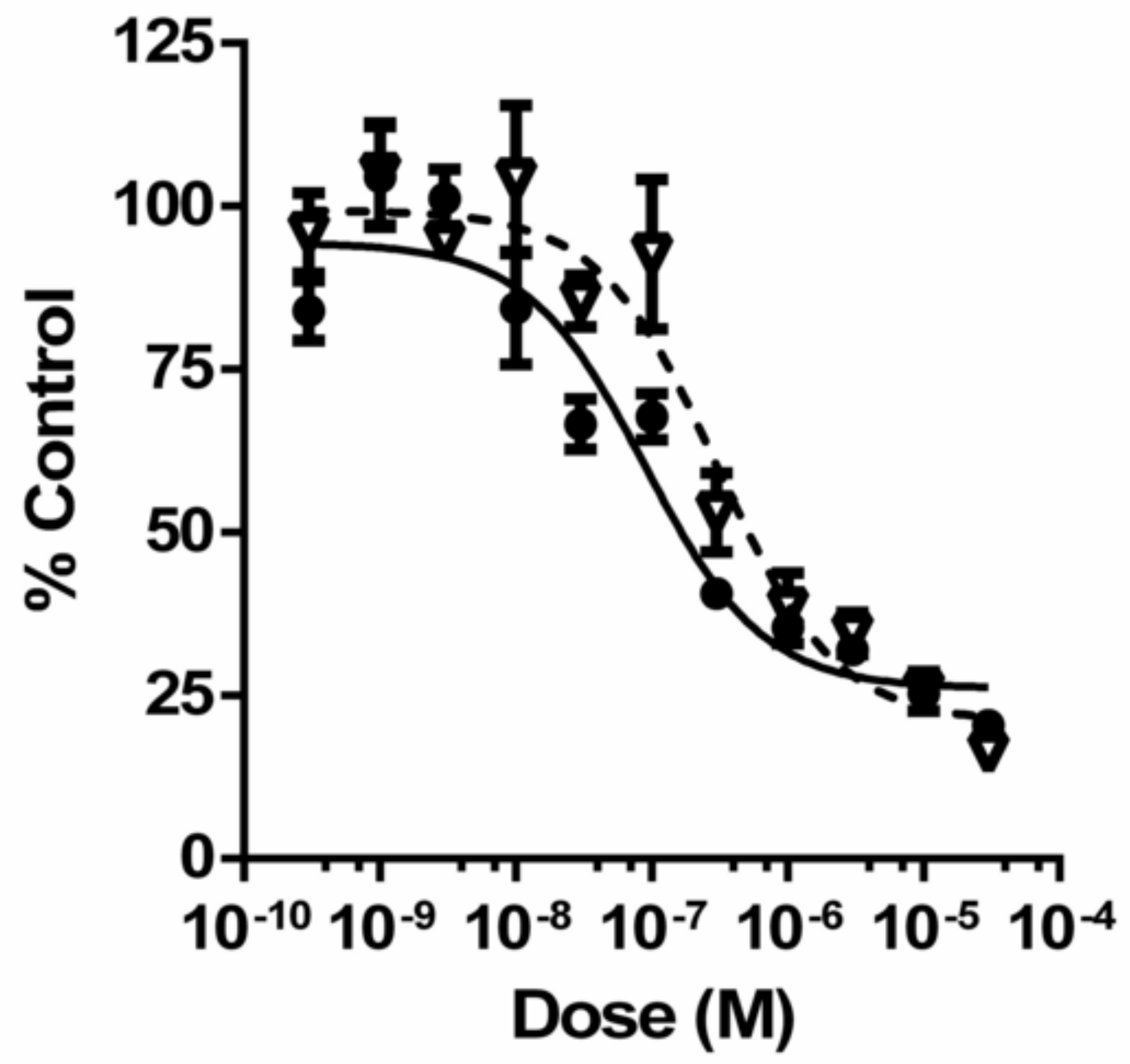




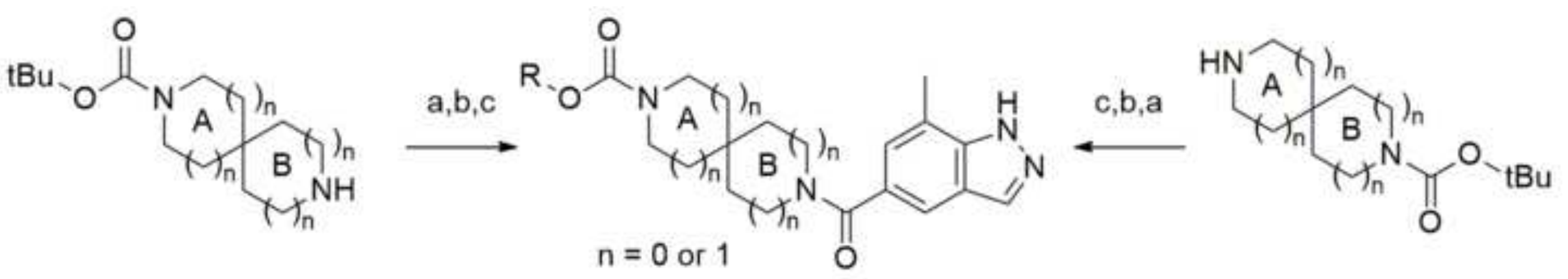




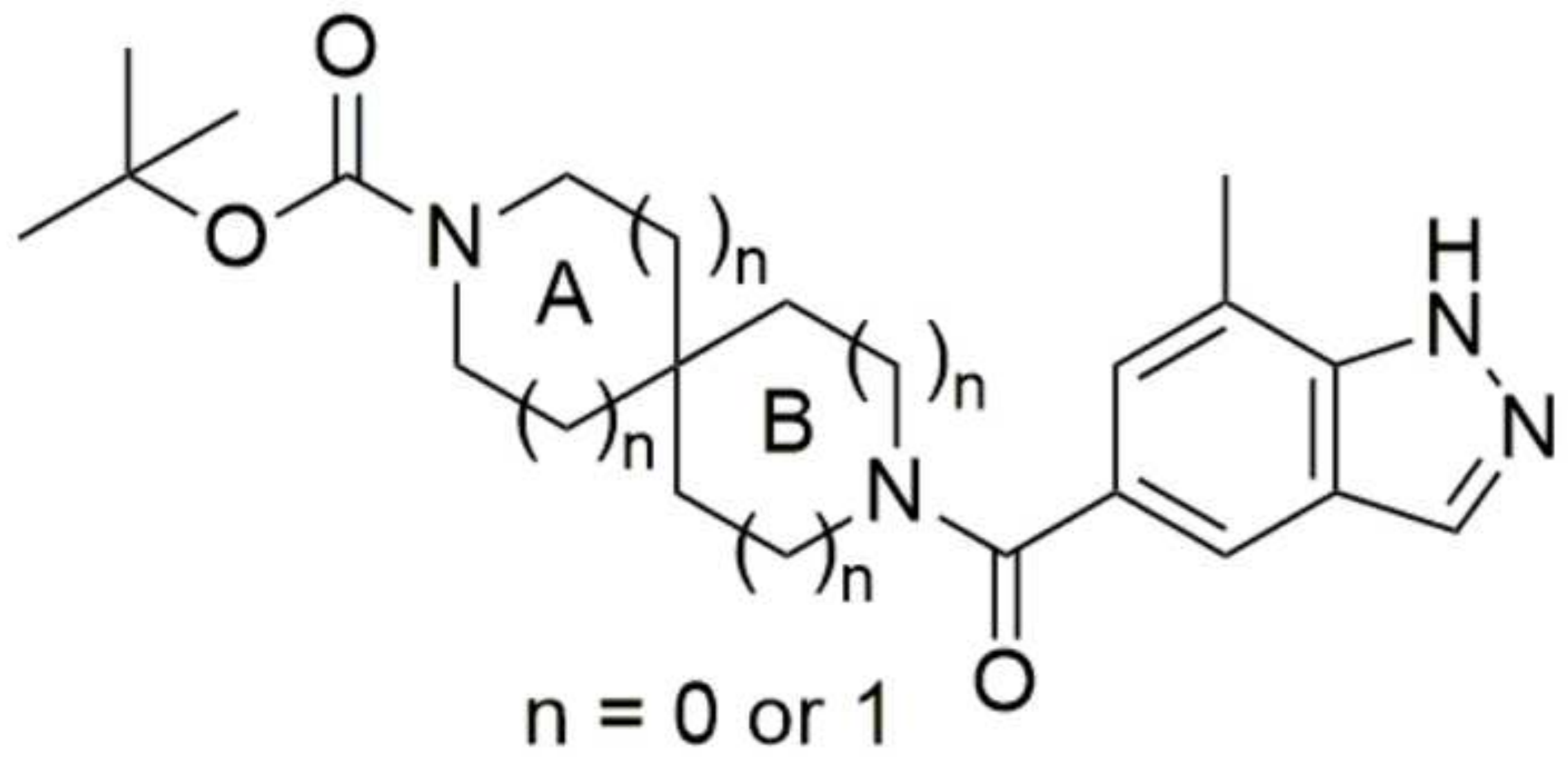



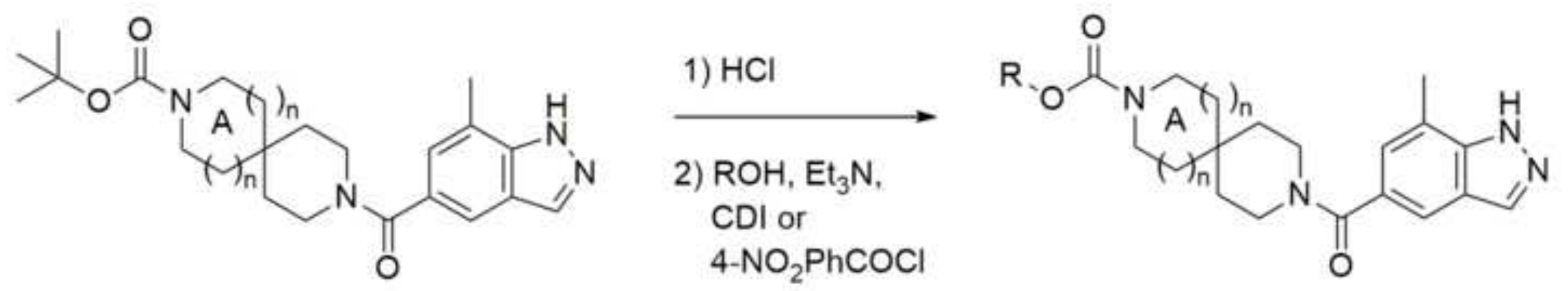


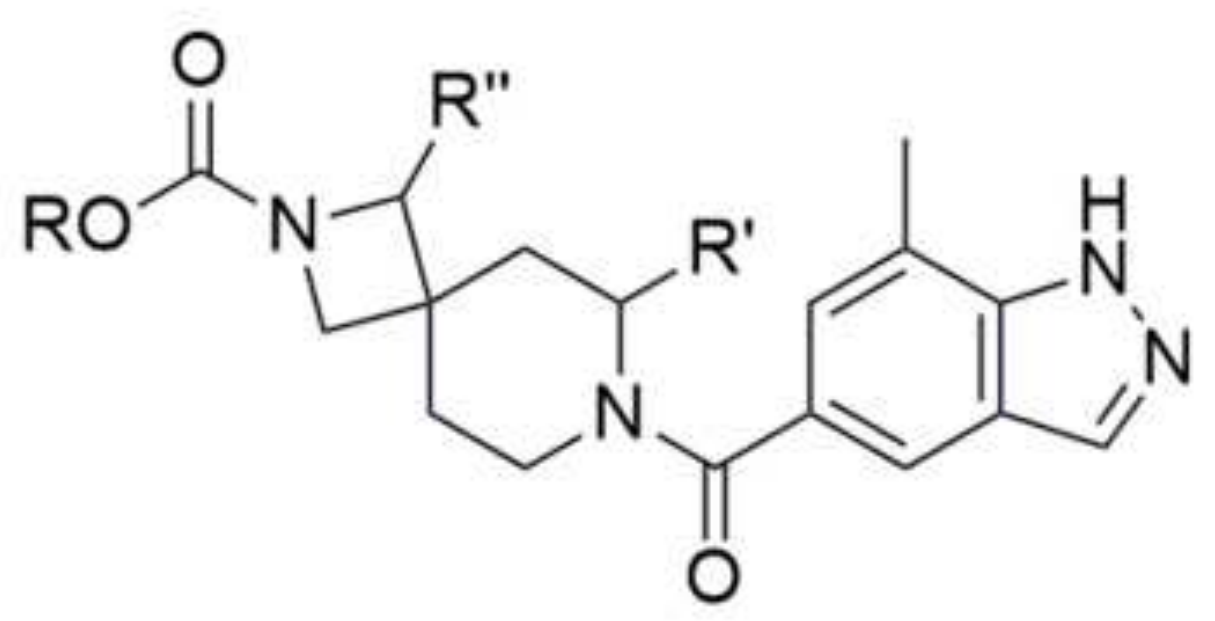

A

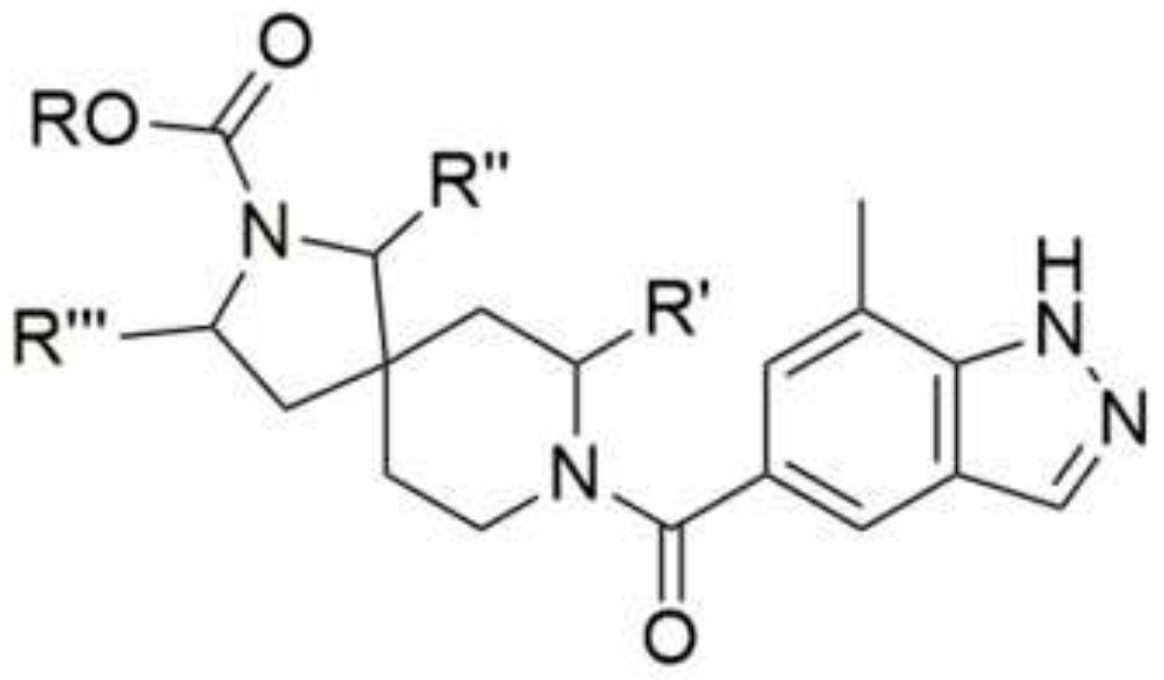

B 